\title{
TRASPLANTE DE LA CIVILIZACIÓN FRONTERIZA DE LA ESPAÑA MEDIEVAL AL NUEVO MUNDO: NOTAS AL FUERO DE SEPÚLVEDA
}

Antonio Linage Conde

Cronista oficial de Sepúlveda

A mi paisano José-Manuel Ortiz, ganadero «in pectore»

Julio Senador, personaje hoy olvidado, es innegable fue uno de los hombres de más acusada individualidad en la España de su tiempo, tanta que quizá por eso tampoco tuvo en su misma época una audiencia correspondiente a lo desbordante de su dicha «humanidad». Notario, desdeñó los ascensos que en la realidad profesional y la estimación social de entonces suponian sustanciosas ganancias y jugoso prestigio, prefiriendo ejercer en pueblos escondidos de la paramera castellana, teatro propicio al ahondamiento de sus amargas y solitarias meditaciones en torno a su geografía y su historia, de donde salían sus libros explosivos, combinatorios de las propensiones anarquizantes con las aspiraciones a la planificación económica y todo envuelto en un sentimiento castellanista hijo del contacto inmediato con el país y no de ordenamiento arbitrista alguno impuesto o siquiera llegado de fuera. El notario de Frómista por autonomasia, que con su sello en tinta que de tal le acreditaba hacía estampar todos los ejemplares de sus ediciones.

En 1919 publicaba en Madrid La canción del Duero. Y con un radicalismo historiográfico detonante para el ambiente e incluso los tiempos sostenía en ella que la realidad de la Reconquista nada tenía que ver con lo que a los estudiantes contaban en los institutos, sino que habia consistido en la lucha del bárbaro pastor cristiano contra el civilizado agricultor árabe. Naturalmente que tal visión estaba más alejada todavía de la veracidad (1) que cuanto en los incriminados institutos pudiera contarse. 
Pero nosotros la hemos traído aquí a colación precisamente a propósito de lo que de trasfondo real había en ella, es decir una cierta constante ganadera innegable en la España reconquistada, hija, no de unos sentimientos ancestrales, raciales o inclusos religiosos, como de las diatribas del notario de Frómista hubiera podido deducirse, sino de la misma base geográfica y humana de aquella evolución histórica.

Y resulta curioso que Julio Senador, pretendiendo arrumbar con toda la interpretación religiosa y heróica de la historiografía más tradicional, incurre en el error irreparable de otra visión unilateral, precisamente por mantenerse aferrado sin darse siquiera cuenta de ello al punto de vista meramente militar de la historia en juego, es decir a la Reconquista sin más y nada más, desconociendo la gemela realidad de la repoblación a ella consecutiva.

Pero la Reconquista, que desde luego existió y fue, sin discusión posible, el factor más decisivo del hacerse peninsular, estuvo acompañada de la repoblación de los territorios con motivo de ella misma vaciados o de los que ya anteriormente eran patrimonio de la tierra de nadie. Lo que nadie pone en duda, aunque sí se haya discutido mucho la despoblación previa sustentada sobre todo por don Claudio Sánchez Albornoz. Y habiendo a la postre de reconocerse que alguna despoblación hubo de haber para que la repoblación fuera posible, puesto que no en todos los casos, extremo éste en el que tampoco la vacilación cabe, se trató de un vaciamiento provocado por las operaciones militares reconquistadoras inmediantamente antecedentes.

Así las cosas, dependiente la repoblación de la reconquista a corto o mediano plazo, se trató casi siempre de una repoblación de frontera, fuera esta frontera de contacto próximo y bajo la amenaza cotidiana y permanente del enemigo, o lo que desde luego era mucho más corriente, con el desierto estratégico, sencillamente la calendada tierra de nadie si lo preferimos, de por medio.

Repoblación que por ser de frontera era arriesgada, y en consecuencia requería de un señuelo para atraerse a los repobladores, señuelo que consistía en un derecho privilegiado, el de los fueros municipales que constituían el ordenamiento jurídico de cada lugar cabeza y su alfoz, el de las autónomas comunidades de villa y tierra. Es la composición de lugar de la búsqueda de gentes para la nueva tierra que, a propósito de la tan audaz repoblación de Sepúlveda por Fernán González el año 940, verdadero salto de tigre entonces por mucho que viniera favorecido por la batalla de Simancas, ha evocado de esta manera con su espléndida prosa fray Justo Pérez de Urbel (2):

Yo también iría -exclama un tercero-, pero no quiero ser tonto. Esos leoneses lo que quieren es que les saquemos nosotros las castañas del fuego. jMuy bonito poblar una ciudad allá, cerca de la 
frontera musulmana, para que antes que llegen a su tierra los toledanos y los cordobeses, los habitantes de Osma, de Gormaz, de Roa y ahora los de Sepúlveda, reciban el primer choque! Yo luché en Simancas como cualquiera de ellos, aquí en el brazo derecho llevo todavía la cicatriz que me dejó una flecha, y mientras ellos se apoderan de las tierras fértiles del Duero - ahí es nada: Baños, Rivas, Ledesma, Salamanca!-, nos dejan a nosotros desiertos y pedregales.

Y con lo que queda dicho ya hemos podido detectar una de las motivaciones del predominio ganadero, sí, solamente con la realidad de estos factores históricos y humanos y al margen de los casos en que hubiera convenido también aquel más que el agrícola por imperativo de la geografía física.

Pues no cabe duda de que a un asentamiento fronterizo y cara a una tierra eremada, le es más favorable la movilidad ganadera, propicia tanto a la expansión como al repliegue según las circunstancias, que el sedentarismo agrícola, cortador de vuelos en las horas alegres y gestador de más irreparables desastres en las tristes.

Incluso antes de la Reconquista ha comprobado para la Mancha lo que acabamos de apuntar uno de los mejores conocedores del tema, Julio González, quien así escribe (3): «La tierras de la Mancha ya habian padecido un proceso despoblador antes de la entrada de los musulmanes. Sus núcleos más importantes de la edad antigua llegaron a sumirse en el silencio; todavía hay discusiones en el intento de identificar las antiguas ciudades con los yacimientos arqueológicos». De manera que «tal circunstancia de decadencia facilitó el éxito de los musulmanes en el siglo VIII, los cuales no hallaron obstáculo en su marcha hacia Toledo. Y se comprueba el asentamiento de bereberes baraníes en el reparto, así como con las revueltas ulteriores». $Y$ ahora estos párrafos que no tienen desperdicio: «La Mancha vino a quedar marcada entre los musulmanes como tierra muy buena para la ganadería y en segundo lugar para los asentamientos agrícolas, dificultados por el paludismo y las razzias. Precisamente su riqueza viaria y su posición céntrica habían de convertirla muy pronto en tierra de tránsito de combatientes y mercaderes, tránsfugas y políticos, así como en tierra de contiendas. No olvidemos que es el puente de unión del Sur con el Centro, Norte y Levante de España (4)».

\section{UN PARALELO EN LA SIGNIFICACIÓN DEL ESPACIO}

No cabe, pues, duda, de que la historia medieval de España se desarrolla en el marco de una tierra nueva. Nueva en cuanto hay que repoblarla con 
de ser trasplantadas de fuera. Novedosidad, en consecuencia, a la que no afecta el remoto arraigo de los pueblos anteriores a la despoblación sufrida (5).

¿Y si ahora volvemos la vista a América? ¿Puede, por su parte, cabernos vacilación alguna de que también tierra nueva es como teatro de nuestra colonización?

Creemos que con lo dicho basta para convenir en que una similitud innegable se da entre la metrópoli y el Nuevo Mundo -epíteto el de nuevo que nada tiene, dicho quede de paso, de lugar común- desde ese punto de vista de la significación en ambos de sus sendas parcelas del espacio para la evolución de sus correspondientes aglomeraciones de humanidad.

Es decir una analogía especifica, concreta, permisiva para el historiador del establecimiento de un paralelo que la mera referencia al espacio no justificaría en cuanto toda historia requiere el marco de una geografía.

Una tierra que pedia hombres y no a la inversa. Cierto que con modalidades y a densidades muy diferentes según los casos, pero sin que en este sentido se pueda hacer tampoco de la Península y de las Indias sendos compartimentos estancos, ya que las tales diferencias se daban dentro de cada uno de ambos territorios. Acabamos de citar, por ejemplo, el caso de la Mancha, «tierra de paso». Volvamos la vista al valle del Duero, «tierra desertizada", y en busca del contraste, al campo murciano y andaluz, tierra de colonización mediante el esfuerzo de las poblaciones vencidas en buena parte.

Diferencias que unas veces son herencia de la situación anterior y otras de la que se crea por la reconquista acá y la conquista allá. Pensemos en las que tan difícil hacen el cotejo entre Andalucía y el Levante citado, por mencionar dos territorios de repartimiento, y ambos poblados hasta el momento de su incorporación por la victoria militar. Y en cuanto a América, ¿a qué buscar en las crónicas lo que la diversidad racial hoy, de unas a otras fronteras, nos está pregonando?

Tierra, pues, demandadora de hombres. Demasiado vasta en ambos casos casi siempre para los recursos demográficos de que se dispone.

¿No se ha hablado del problema para la repoblación peninsular? Así escribe Salvador de Moxó (6) de una de sus parcelas llamadas a más aureolada repercusión a la postre: «El volumen de la despoblación en el solar primitivo de Castilla y en el de la segunda Castilla de Burgos y Amaya contribuye a explicar, junto con la habitual actividad ofensiva militar de esta comarca, lo paulatino y azaroso de la repoblación, así como lo poco tupida que se ha- 
llaba aún la red de ésta a fines del siglo IX. Las presuras de tierras yermas continúan a lo largo del siglo $X$ y la expansión de los límites fronterizos cristianos se hace aqui con mayor lentitud que en la zona occidental del reino asturleonés».

Y en cuanto al Nuevo Mundo, baste con echar una ojeada al mapa y tener en cuenta que a lo largo de toda la etapa del imperio ultramarino España no pasó de oscilar entre los ocho y los doce millones de habitantes. «Uno de los rasgos más importantes de este medio fue su tamaño gigantesco, y por lo tanto el gigantesco tamaño del imperio - ha escrito Salvador de Madariaga (7)-.. A decir verdad, lo que ha menester explicación no es tanto el derumbe del imperio como el milagro de su persistencia trisecular. Los territorios confiados al dominio español excedian en un quinto al continente europeo; pero además su forma peculiar, con un reino al norte del istmo, y todos los territorios del sur dispersos en arco de círculo en torno al Brasil y entrecortados por la cadena de montañas menos franqueable del mundo después del Himalaya, más las islas dispuestas en otro arco de círculo a través de la parte más vulnerable del Atlántico. Así destartalado de polo a polo, ofrecía el Nuevo Mundo español en sus millares de leguas de costas centenares de bahías, de estuarios, de islas» (8).

\section{LA CONSTANTE GANADERA}

Pero aun creyendo posible, como queda dicho, descubrir sin demasiado esfuerzo un parentesco entre la España del Viejo y la del Nuevo Mundo en el desafío del espacio al hombre y la toma de postura de éste frente a ése, no vamos a negar que los lazos son mucho más íntimos si pasamos al análisis del aprovechamiento ganadero (9) que quizás sea la clave de la tal respuesta humana a la dicha exhortación geográfica e incluso histórica (10).

Una respuesta la ganadera que se dio ya en la repoblación monacal (11), de los siglos VIII al $X, y$ luego en la concejil de las dos centurias siguientes, es decir, anteriormente a la supuesta fundación de la Mesta en 1272, y que coadyuvó al acuñamiento de la psicología colectiva del hombre de aquella Castilla como nuevo territorio dotado de propia personalidad al volver a la vida el marco físico de su desarrollo (12), acuñamiento para el que resultó esencial la condición trashumante, hasta más allá de la sierra de Guadalupe y de los montes de Toledo.

Pero cuanto en detalle tratáramos de decir en este capítulo sería ocioso luego de la eruditísima puesta al día del estado de la cuestión por CharlesJulian Bishko (13) a los sesenta años de la publicación de la monografía deci- 
siva sobre el tema de su compatriota Julius Klein (14).

$Y$ que ese alarde de "benedictina" sapiencia libraria nos llegue de los Estados Unidos no es en este caso una confirmación más de la apertura de ese país al cultivo de los dominios foráneos. Ni mucho menos.

\section{SU EXTENSIÓN A LA AMÉRICA ÁNGLICA}

Puesto que en los vastos territorios otrora hispanos por los cuales extendió el poderoso vecino del norte su frontera meridional, y aun más allá, esa civilización fronteriza asentada en una economía y una mentalidad pastoriles sobrevivió al cambio de dominio.

Es lo que se ha hecho notar una vez más recientemente (15) al estudiar el rancho colonial importado de la madre patria. En tanto que las otras dos instituciones en juego, la misión y el presidio (16), se quedaron como memorias nostálgicas, desde luego que bien, ejemplarmente mantenidas en el recuerdo tal por los nuevos dominadores al cambiar los límites territoriales.

Y es esa ganadería de frontera la matriz de toda esa marcha hacia el oeste, esa epopeya deformada por el desaprovechamiento cinematográfico, que la sacrificó estúpidamente a la suficiencia falsa y la violencia burda, de una especie literaria digna de mejor suerte. $Y$ ahí está el libro de Pierre Chaunu, L'Amérique et les Amériques, de los más jugosos entre los suyos y ya es decir, con su evocación de ese hervidero de inquietud espiritual que en dicho Extremo Occidente se manifestó a través de la eclosión desbordante de sectas religiosas. En enlace consecuente, y no en oposición explicatoria por la ley del contraste, con toda esa misma civilización del cow-boy (17).

\section{LA FRONTERA ABIERTA DEL ALFOZ SEPULVEDANO}

Así las cosas, vamos a retornar a los invocados precedentes del proceso peninsular.

El año 940 Fernán González repuebla Sepúlveda. Ello implica un formidable avance, lleno de riesgos, hacia la línea musulmana. Circunstancia que no podemos preterir. Como tampoco la topografía de la villa, pintiparada fortaleza natural, un escarpe medianero entre los cañones del Duratón y el Caslilla, ni más ni menos.

Sobre todo la primera, aunque coadyuvando también esta segunda, nos explican sin más que la población, rediviva después del interludio subsiguiente a su eremación en las campañas de Alfonso I, sea la cabeza de aquella Extremadura castellana, con la leonesa la única respondente a su etimología, 
de tierras extremas del Duero. Si bien no discutiremos este detalle semántico muy controvertido.

Y el elemento diferenciador de aquella Sepúlveda era su derecho privilegiado, su ordenamiento jurídico propio, su fuero. Ordenamiento jurídico no sólo peculiar sino autónomo, teniendo en cuenta las facultades en él mismo atribuidas al concejo que acabaron de hecho convirtiendo a éste en órgano creador de derecho a su vez, en el núcleo aglutinante de la evolución consuetudinaria de aquel derecho foral mismo, y así transformador a la postre de aquel fuero breve latino en el correspondiente castellano extenso.

Y es curioso cómo en este trance historiográfico, cuando un tanto liberados de la obligada servidumbre del atornillamiento bibliográfico de nuestras afirmaciones, por habernos ya sometido a él en varias ocasiones de alguna coincidente temática y otro enfoque, nos hemos concedido una vacancia meditadora, vemos las cosas más claras, aun reconociendo que sujetas, ¿cómo no?, a revisión.

Y es esa indole del derecho de Sepúlveda como equivalente al derecho de esa Extremadura sin más. Y no sólo del de la Extremadura castellana, sino por la prioridad cronológica respecto de ellas y la comunidad de la coyuntura fronteriza y repobladora ante todo, también del de las otras Extremaduras anteriores a la definitiva de hoy, la leonesa y la aragonesa. Ahi está la problemática de las conexiones con él del Fuero de Béjar (18) y su indubitada concesión tardía a Teruel y Albarracín.

"Y dentro del derecho castellano (19), Sepúlveda es el centro creador de su especialidad de Extremadura, que modela la organización jurídica de toda Castilla, directamente o mediante el Fuero de Cuenca", pero teniendo en cuenta que este «Fuero de Cuenca es la fijación tardía y por escrito (20) del derecho de Extremadura" nada más, o sea la redacción del derecho sepulvedano creado en y desde Sepúlveda. Y es más, "cuando a principios de la Edad Moderna se revisa la historia del derecho medieval, y las leyes de Toro armonizan las contradicciones surgidas en su seno, la nueva síntesis tiene como rasgo dominante la decisión del derecho castellano y Sepúlveda es la sede del Derecho civil común de España». Estas afirmaciones de Rafael Gibert, al editarse al fin rigurosamente el derecho sepulvedano (21), no han perdido su valor ante las aportaciones, desde luego bastante numerosas y densas, de la bibliografía surgida en los treinta años posteriores.

Pues bien, dejando ahora de lado estos horizontes de su propagación, y volviendo al momento del otorgamiento regio del ordenamiento jurídico sepulvedano y de la consiguiente autonomía (22) de su comunidad de villa y 
tierra, o sea del alfoz de Sepúlveda, nos interesa fijarnos en los límites territoriales de éste según aparecen determinados en el fuero latino, o sea en el genuino de Alfonso $\mathrm{VI}$, el año 1076 (23). Concretamente en el detalle de carecer de frontera meridional, o sea cara a la tierra enemiga (24). Atilano González Ruiz-Zorrilla (25) comenta a ese propósito que tal inexpresado linde «podía muy bien estar formado por las sierras que se extienden desde el nacimiento del Ayllón hasta el nacimiento del Pirón». Pero Jean Gautier-Dalché (26) ha sabido ver posteriormmente con agudeza que no hubo tal. Sino que sencillamente el monarca otorgante no quiso poner puertas al campo sureño y que al alfoz le quedaba una expansión ilimitada por aquel lado de la tierra de nadie, al otro lado de la cual se toparía con la media luna; tan ilimitada como sus fuerzas y su audacia se lo permitieran (27).

¿Y es mucho pedir por nuestra parte si ahora, sólo por un momento, reclamamos de nuevo trasladarnos al panorama de los ranchos de Indias?

\section{LABRADORES CONTRA PASTORES}

En un interesante estudio, el letrado segoviano Manuel González Herrero (28), escribió que «el ordenamiento pastoril de Sepúlveda se inspira en el respeto y protección de los intereses de la agricultura, como corresponde a un derecho de frontera - derecho de la Extremadura castellana- nacido para servir las finalidades de la empresa de fijación y repoblación del territorio, y preocupado por tanto de favorecer mediante un estatuto personal, político, jurídico y económico privilegiado, el asentamiento de las gentes en las tierras recién ganadas y el laboreo de las mismas». Y efectivamente, consiguió citar en su apoyo unos cuantos preceptos forales que protegían las tierras de labor contra los daños en ellas ocasionados por los rebaños.

Y nosotros no vamos a negar que las aspiraciones de la potestad condal o regia repobladora eran el asentamiento definitivo de los repobladores en la nueva tierra, tal y como ninguna otra ocupación cual la agricultura sedentaria puede proporcionarla. Pero por eso mismo no podían pasar de ser una aspiración a largo plazo. Pues la frontera no estaba segura ni se sentía como fija. Ya que en otro caso, aun habiendo la tal frontera existido, ni la civilización hubiera sido fronteriza ni el derecho foral necesario. Eso por un lado. $Y$ por otro, la contrapartida. Pues esa misma falta de fijación de la tal frontera, si de un lado actuaba en el sentido de moderar exigencias y conformarse con lo que a la vista había, de otro implicaba un estímulo a ensancharla, a llevarla más allá, a tornar esa su misma indeterminación en el propio beneficio. Y nada mejor para ello, aparte la atención al elemento bélico estricto, que la for- 
mación de unos intereses ganaderos necesitados de expansión por la parte del mediodía. La de la trashumancia, no lo olvidemos, la de los pastos de invierno, una constante biológica señuelo desde las aves hasta los hombres. De ahí que aquellos preceptos de protección a la agricultura haya más bien que mirarlos como las obligadas y mínimas limitaciones a un contexto abrumadoramente pastoril. «Y lo aumentó, dándola más término sobre los límites que antes tenía», es la frase de don Juan de la Reguera Valdelomar (29) que en las postrimerías del antiguo régmen captó lo esencial de aquella situación y la mentalidad a ella conformada. Como don Ignacio-Jordán de Asso y del Río y don Miguel de Manuel y Rodríguez (30), al referirse al derecho coetáneo extremo-castellano todo (31), hablen por su parte, y acentuando ya más lo castrense específico y primigenio de «las condiciones y pactos en que convinieron para servir en la guerra contra los africanos» $y$ «un código militar» a su servicio".

\section{LA APERTURA DE LOS CAMPOS}

Yo diria que en los textos legales o en los doctrinales y aun literarios con cierto valor de observancia - tal aquellos códices del abad o codices regularum donde, en el estadio monástico prebenedictino se contenía la regula mixta o sea la disciplina cenobítica aplicable - anteriores a las modernas codificaciones sucesoras del más o menos barroquismo legislativo del Antiguo Régimen, el orden de los factores sí que alteraba un poco el producto. Es decir, que la colocación de los preceptos jurídicos denotaba un tanto su rango legislativo.

$Y$ en este sentido, podemos aquí fijarnos en el título primero del Fuero Extenso de Sepúlveda, con la contundencia de su titulación, que toda Estremadura sea tenida de venir a Sepúlvega a fuero.

Es la consagración por el derecho escrito de aquella la verdad histórica alumbrada también por la geografía y a la que arriba nos referíamos de ser Sepúlveda la cabeza de Extremadura.

Rotundidad en el dicho título que no cede un ápice en los pormenores de su desarrollo. Pues si bien su sustancia es una referencia a la delimitación de los términos del alfoz ya hecha en el preámbulo -aprimas do e otorgo a los que moran en Sepúlvega e a los que son por venir Sepúlvega con todo su término - el corolario que a su vez explaya la misma no deja de implicar una cierta vocación de campo sin puertas. Un tanto la gozosa nostalgia de aquella la siempre abierta frontera - jo carencia de ella! - meridional de antaño. Con montes et con fuentes, estremos, pastos, ríos, salinas, venas de 
plata e de fierro e de cualquiere metallo. Estremos, o sean pastos de invierno de la trashumancia (32) con caminera vocación de libertad y horizontes (33). Campos abiertos, como precisaba la confirmación por Alfonso VIII desde Riaza, a 20 de julio de 1207, del acuerdo entre los concejos de Sepúlveda y Fresno de Cantespino: super illo quod debet esse "extremum", videlicet, quod non laboret illud nec populet concilium de Sepúlvega nec concilium de Fresno set quod remaneat per ad los pastos et los pastos sint de comun (34).

Campos abiertos como los de la Nueva España y el Nuevo Mundo tout court. Campos abiertos como los que hacia el Oeste pasaron tardíamente la frontera de la América ánglica. Con su forzado encarrilamiento jurídico a la postre por la Mesta que, si de un lado, llevaba consigo el reconocimiento de haber algunas puertas en los horizontes ya trillados, al menos consagraba la libre potestad natural de vagar a su través. 


\section{NOTAS}

(1) Creemos que en el momento actual, un cierto peligro de alejarse de la realidad histórica sería ceder a las lisonjas de una cierta apologética de lo árabe. Concretamente en el ejemplo de Julio Senador, no vamos a negar las virtudes labradoras de ellos en nuestra tierra, pero no olvidemos, por botón de muestra, la reciente tesis del origen romano y no islamita de los regadios de la huerta valenciana. Cfr. F. UDINA MARTORELL, La Reconquista española, en «La cristiantà dei secoli XI e XII in Occidente: Coscienza e strutture di una società» (VII Semana de Mendola, 1980; Milán, 1983), pp. 85-101.

(2) Fernán González, el héroe que hizo a Castilla (Buenos Aires, 1952) pp. 85-6.

(3) La repoblación de la Mancha, en el volumen colectivo "VII centenario del infante don Fernando de la Cerda. 1275-1975; (Ciudad Real, 1976), pp. 1-3 de la separata.

(4) Apostillando todavía que «las luchas civiles del siglo IX con sus campañas y razzias contribuyeron a mantener y aun aumentar la desertización». Por lo tanto no podía quedar mejor preparado el terreno para la necesidad repobladora subsiguiente a la reconquista: «La muy escasa densidad humana durante el siglo $X$ se prolongó en el $\mathrm{Xl}$ ».

(5) En este sentido yo vengo calificando repetidamente de segundo nacimiento el que para la villa de Sepúlveda tiene lugar con la repoblación de Fernán González.

(6) Repoblación y sociedad en la España cristiana medieval (Madrid, 1979) p. 41.

(7) Cuadro histórico de las Indias (2. ${ }^{\mathbf{a}}$ ed., Buenos Aires, 1960) p. 369.

(8) Cfr. A. Rumeu de Armas, América en el horizonte. (Glosas ante la efemérides del $V$ centenario), en «Revista General de Marina», 203, octubre 1982, 183-6.

(9) Don Ramón de Carande ha escrito que «ninguna manifestación de la vida económica española tiene en su historia el arraigo que la ganaderíam, Carlos $V$ y sus banqueros, I (Madrid, 1943) p. 47

(10) C. J. BISHKO (The Iberian background of Latin America History: recent progress and continuing problems, en «Hispanic American Historical Review», 36, 1956, 50-80; y The peninsular background of Latin American Gattle ranching, en ibid., 32, 1952, 491-512) valora conjuntamente la doble influencia del pasado reconquistador y repoblador fronterizo ("of the frontiers) en el trasplante americano, a saber la herencia de sthe long southward advance against powerful military foes, the acquisition of abundant territory and the necesity of colonizations.

(11) Y más que en la etapa inicial y predominante de ésta en su consolidada sucesión en los grandes centros consecuencia de la concentración monástica, o sea en su etapa ya señorial y latifundista.

(12) R. PASTOR, La lana en Castilla y León antes de la organización de la Mesta, en «Moneda y Crédito", núm. 112 (marzo 1970), 47-49; y C. J. BISHKO, The Castilian as Plainsman: The medieval ranching frontier en la Mancha and Extremadura, en "The New World looks at its history", ed. A. R. Lewis y T. F. McGann (Austin, Tejas, 1963); traducido, El castellano hom- 
bre de llanura, en “Homenaje a Jaime Vicens Vives», I (Barcelona 1965), pp. 201-18.

(13) Sesenta años después: “La Mesta» de Julius Klein a la luz de la investigación subsiguiente, en «Historia. Instituciones. Documentos», 8 (1982), 1-49 (separata).

(14) The Mesta: a Study in spanish economic history. 1273-1836. («Harvard Economic Studies» 21; Cambridge, Mass., 1920) Cfr. F. CHEVALIER, La formation des grands domaines au Mexique: terre et societé aux XV/•-XVI/ siècles (París, 1952); y él mismo, Vingt-cinq ans de nouvelles recherches sur les grands domaines au Mexique: un bref bilan, en «Melanges de la Casa Velázquez», 11 (1973), 119-29. Para vinculaciones a otros territorios, H. EPSTEIN, The origins of the domestic animals of Africa (Nueva York-Londres, 1971), pp. 1-191 (en torno al «misterio» de la oveja merina). Bishko concluye que «a menos que consideremos que el pasado es sólo el campo de juego de la econometría, La Mesta no puede ser relegada a la categoría de un manual útil sólo para el conocimiento de los aspectos institucionales, administrativos o de historia événementielle".

(15) S. L. MYRES, The Ranching Frontier: Spanish institutional backgrounds of the plains cattle industry, en «New Spain's Far Northern Frontier. Essays on Spain in the American West, 1540-1821. Ed. David J. Weber" (Universidad de Nuevo Méjico, Alburquerque, 1979), pp. 79 94. Antes: W. P. WEBB, The great plains (Boston, 1931); y O. FAULK, Ranching in Spanish Texas, en «Hispanic American Historical Review», 44, (1965), 257-66. Intentos revisionistas de esta tesis: J. D. W. GUICE, Cattle raisers of the Old Southwest, en "The Western Historical Quarterly" 8, (1977), 167-87; y T. JORDAN Early Northeast Texas and the evolution of Western ranching, en "Annals of the Association of American Geographers» 67 (1977), 67-87.

(16) En el sentido de fortaleza, por supuesto. Véase H. E. BOLTON, The Mission as a frontier institution in the Spanish American colonies, en "The American Historical Review» 23, (octubre 1917), p. 42.

(17) Escribe Myres (p. 84 de su libro citado en la nota 15): «Both the roundup and the drive were perfected by the spanish ganaderos ("cowmen») long before the first Texas cowboy ever tossed a rope over a Longhorn Steery. Para no perder de vista los factores precedentes a la conquista, cfr. C. MINGUET, Alexander de Humboldt historien et géographe de l'Amérique espagnole. 1799-1805 (París 1969), pp. 205-6.

(18) Véase J. GUTÉRREZ CUADRADO. El fuero de Béjar (Salamanca 1975). El criterio de su editor, de atender a la precedencia entre los textos escritos, y aun a los manuscritos conservados más bien, en detrimento de la que afecta a la sustancia de lo en ellos consignado, o sea del contenido, nos lo hace poco aprovechable a nuestros propósitos. Cfr. A. LINAGE CONDE, De Sepúlveda a Teruel y Albarraciin: en torno a la prioridad foral, en «Homenaje al profesor Martín Almagro Basch»IV (Madrid, 1983), pp. 147-54; y el mismo, El Fuero de Sepúlveda en la gestación del derecho de Teruel, en «Jerónimo de Zurita. Cuadernos de Historia», núms. 49-50 (1984), pp. 7-29.

(19) La réplica de A. GARCIA GALLO (Aportación al estudio de los fueros, en «Anuario de Historia del Derecho Españols 26 (1956), 387-446) no tuvo en cuenta esta limitación de las aseveraciones que transcribimos a la Extremadura castellana. $O$ sea que era más bien terminológica. La contrarreplicó el mismo GIBERT [El derecho municipal de León y Castilla, en íbid. 31 (1961), 695-753]. Una reseña del mismo Garcia Gallo [ibid. 50 (1980), 733-7], publicada casi un cuarto de siglo después, nos parece ser un cierto asentimiento a la postura por él al principio combatida, una vez deshecho el tal equivoco y hecha más luz por las investigaciones posteriores.

(20) Pero «la fijación por escrito es propiamente la decadencia del derecho castellanom. Insiste en la limitación a este ámbito subordinado de la prioridad conquense, aun sin conceder la sepulvedana, J. MARTÍNEZ GIJÓN, El régimen económico del matrimonio y el proceso de redacción de los textos de la familia del Fuero de Cuenca, en «Anuario de Historia del Derecho Español» 29. (1959), 45-151. 
(21) E. SÁEZ, él mismo, M. ALVAR Y A. GONZÁLEZ RUIZ-ZORRILLA, Los Fueros de Sepúlveda (Segovia, 1953), pp. 547-8.

(22) Cfr. M. GONZÁLEZ HERRERO, La entidad histórica de Segovia. Raíz y fundamentos de la autonomía (Segovia 1981); y A. GARCÍA SANZ y J. MUÑOZ, Manipulación y falseamiento de la historia de Segovia y de Castilla. A propósito de la cuestión autonómica segoviana (Madrid 1982). También J. VALDEÓN, Aproximación histórica a Castilla y León (Valladolid 1982); a la p. 115 de esta última, «ahora bien, la búsqueda de las señas de identidad específica de Castilla y León no es tarea fácil». Y a la p. 30, su confirmación de que "Castilla y León nacieron en el transcurso de este proceso repoblador de la cuenca del Duero cuyas primeras fases se desarrollaron en los siglos IX y $X » 0$ sea en los días de la repoblación sepulvedana

(23) No nos interesan ahora sus precedentes concesiones descie Fernán González, que no nos han llegado escritas, y de las cuales el texto alfonsino se presenta como la confirmación, aunque podamos suponer sea modificatoria en algún extremo. Pues la persistencia el año 1076 del estado de cosas a que vamos a aludir, va toda a favor de nuestra argumentación aquí.

(24) El inserto de Lozoiha usque huc quantum Butrago habuit in sua potestate es ensanchador, un añadido, pero no un límite.

(25) Autor de la parte dedicada a los «términos antiguos de Sepúlveda» en el volumen citado en nuestra nota $21 ;$ p. 877.

(26) Recherches sur I'histoire urbaine en Leon et en Castille au Moyen Age (tesis inédita, París 1971); versión sin notas ni documentos, Historia urbana de León y Castilla en la Edad Media. Siglos IX-XIII (Madrid 1979)

(27) En el fuero extenso, dos siglos más tarde y ya con otras potestades cristianas constituidas al dicho mediodia, repoblado con creces y antes de lo que al parecer en 1076 se había previsto - recordemos esa fecha tan cercana a este año del 1085-la situación era radicalmente diferente, y en consecuencia la frontera sur aparece trazada con la misma precisión que la de los otros tres puntos cardinales.

(28) Sobre la jurisdicción de la Mesta en Sepúlveda, en «Estudios Segovianos» 18 (1966), 5-20 (separata).

(29) Extracto de las leyes del Fuero Viejo de Castilla, con el primitivo Fuero de León, Asturias y Galicia. Se añaden el antiguo Fuero de Sepúlveda y los concedidos por San Fernando a Córdoba y Sevilla. Formado para facilitar su lectura y la instrucción de sus disposiciones (Madrid 1798), núm. 16 del prólogo sin paginar.

(30) El fuero Viejo de Castilla, sacado y comprobado con el ejemplar de la misma obra que existe en la Real Biblioteca de esta Corte y con otros manuscritos (Madrid 1791), p. vi.

(31) Cfr. A. M. BARRERO, El derecho local, el territorial, el general y el común en Castilla, Aragón y Navarra, en «Diritto comune e diritti locali nella storia dell'Europa», actas del Congreso de Varenna de 1979 (ed. Giuffré, 1980), pp. 274-5, nota 23.

(32) Lo que sin embargo no nos induce a derivar la etimologia de la actual Extremadura de "tierra de invernación de los ganados», sino del corrimiento de la frontera hacia el sur. ¿Y la segunda parte del vocabio, el Durii? ¿Y los ejemplos de los otros corrimientos, leonés y aragonés, y el castellano mismo en tierras de Castilla la Nueva?

(33) Bishko hace constar que en Castilla la Vieja sólo han sido documentadas las mestas de Sepúlveda y Barco de Ávila; artículo citado en la nota 13, p. 25.

(34) Edición citada en la nota 21,p. 726. Cfr. título 105, del qui cerrare carrera o exido; y 252 , del que oviere erencia en frontera. 